\title{
SUCESION EN EL TIEMPO DE LA NORMA DE CONFLICTO Y LEY RECTORA DEL ESTATUTO PERSONAL DEL APATRIDA
}

\section{Por JOSE CARLOS FERNANDEZ ROZAS}

Universidad de Oviedo

SUMARIO: $\S 1$. Introducción. - $\S 2$. Delimitación del problema e hipótesis en presencia. $§ 3$. Sucesión en el tiempo de normas de conflicto legislativas. - $\$ 4$. Norma de conflicto consuetudinaria o jurisprudencial modificada por una norma de conflicto legislativa. $-\S 5$. Sucesión en el tiempo de normas de conflicto derivadas de la entrada en vigor de un tratado.

\section{§1. INTRODUCCION}

1. Una serie de factores están situando en un primer plano de actualidad los problemas de Derecho intertemporal derivados de las relaciones del tráfico juridico externo en el Derecho español (1). Entre ellos cabe señalar, en primer término, las modificaciones experimentadas en los últimos años por nuestro sistema de Derecho internacional privado y que han afectado sensiblemente al ámbito del Derecho de la nacionalidad (Ley 14/1975, de 2 de mayo, $R$. Decreto-ley 33/1978, de 16 de noviembre),

(1) Sobre la dimensión general del problema de las relaciones entre los conflictos de leyes en el espacio y los conflictos de leyes en el tiempo vid., con carácter general, $\mathrm{H}$. Batiffol, "Conflits de lois dans l'espace et conflits de lois dans le temps", Le droit privé français au milieu du XX $X^{\mathrm{e}}$ siècle (Etudes offertes à Georges Ripert), París, LGLJ, 1950, pág. 292 y sigs. 
del Derecho de extranjería (Decreto 522/1974, de 14 de febrero, R. Decreto 1874/1978, de 2 de junio, R. Decreto 1884/1978, de 26 de julio...) y, sobre todo, al del conflicto de leyes (Decreto 1836/1974, de 31 de mayo). En segundo término, la progresiva integración de nuestro país en el régimen convencional internacional de las relaciones privadas internacionales, tanto a nivel multilateral como bilateral, como consecuencia del reciente proceso de reforma política. Finalmente, la entrada en vigor de la Constitución de 1978 y la consiguiente necesidad de revisión de sectores sustanciales de nuestro sistema en un futuro inmediato.

Pero la actualidad de los conflictos intertemporales no deriva sólo de la situación de cambio que registra el Ordenamiento jurídico español desde el punto de vista legal y convencional. Se refleja, asimismo, en la concepción mantenida por nuestros Tribunales acerca de ciertos principios considerados hasta la fecha como intangibles (pensemos, por ejemplo, en la indisolubilidad del vínculo matrimonial). De este modo, se asiste a un aumento de los supuestos del tráfico jurídico externo en los cuales, entre el momento de nacimiento de la situación y el del fallo del Tribunal, se ha producido una variación del concepto de orden público. En estos casos, como ha señalado M. de Angulo, la tesis de la actualidad del orden público suele desplegar toda su eficacia (2).

2. El panorama descrito se encuentra en gran parte reflejado en la Sentencia de la Audiencia Territorial de Granada de 12 de febrero de 1975

(2) Vid. M. de Angulo, «Du moment auquel il faut se placer pour apprécier l'ordre public international», Rev. Crit. Dr. Int. Pr., 1972, págs. 369-399. La Sentencia del Tribunal Supremo (Sala $l^{a}{ }^{a}$ ) de 22 de noviembre de 1977 («María P. M. c. Emérico P. M.») es una buena muestra de la evolución de la noción del orden público en nuestro sistema. In casu, ante una demanda de separación conyugal interpuesta por la esposa, el marido reconvino solicitando la nulidad en base a que con anterioridad a su matrimonio civil, contraído con la actora en 1943 en Madrid, él había celebrado otro, también civil, en 1928 en Hungría, el cual, posteriormente, había sido disuelto por divorcio. La alegación del recurrente de que tal disolución del vínculo «chocaba con el orden público» dominante en España en la fecha de su segundo matrimonio no fue, sin embargo, aceptada por el Tribunal Supremo Demostrativo del cambio de concepción sufrido por nuestro Alto Tribunal acerca de la indisolubilidad del vínculo matrimonial es el siguiente Considerando: "Que como acertadamente proclaman múltiples Resoluciones de la Dir. Gral. de los Registros, la indisolubilidad del matrimonio es esencialmente básica en la organización de la familia e integrante del orden público español, pero no es una regla absolutamente rigida, pues admite inflexiones, y con mayor razón ha de admitirlas cuando se trata de matrimonios que, por la nacionalidad de los cónyuges, han de regirse, según las normas españolas de conflicto, por leyes extranjeras, si según éstas se admite el divorcio vincular" (Aranzadi, Repertorio Jurisprudencia, 1977, núm. 4.284; J. D. González Campos (con la colaboración de J. C. Fernández Rozas), Prácticas de Derecho internacional privado, 6. ${ }^{\mathrm{a}}$ ed. vol. I, Oviedo, Serv. Publ. Universidad, 1978, págs. 218-221 -el subrayado es nuestro-). 
("Swinkels c. Swinkels») (3), donde se suscitó con nitidez la insuficiencia de la normativa en vigor -Decreto $1836 / 1974$ - que no había previsto una solución de Derecho transitorio ante un problema de sucesión en el tiempo de una norma de conflicto.

A propósito de esta decisión consideramos oportuno realizar unas reflexiones de carácter general acerca de la incidencia del factor tiempo en el Derecho internacional privado español a través de sus distintas manifestaciones. Esta oportunidad se ve, además, acrecentada por el hecho de que el supuesto aludido presenta una interesante especialidad: se trata de la sucesión de un apátrida en nuestro país, acaecida poco antes de la reforma del Título Preliminar del Código Civil.

\section{§ 2. DELIMITACION DEL PROBLEMA E HIPOTESIS EN PRESENCIA}

3. Aunque la aludida sentencia plantee el problema intertemporal en el plano del conflicto de leyes, no puede desconocerse que éste se suscita igualmente en los otros sectores que conforman el contenido de nuestra disciplina. Dicha incidencia, en mayor o menor medida, ofrece ciertas particularidades distintivas de las reglas generales del Derecho transitorio:

A) Así, en el ámbito del Derecho de la nacionalidad, la sucesión en el tiempo de normas distintas sobre adquisición o pérdida de la nacionalidad puede afectar decisivamente a ciertos facta pendentia. Pensemos, por ejemplo, en la incidencia que tuvo el artículo 20 del Fuero de los Españoles sobre el artículo 34 del Código penal respecto a la pérdida por sanción de la nacionalidad española por los nacionales de origen (problema resuelto en la actualidad por el artículo $11,2 .^{\circ}$ de la Constitución) (4). En la misma dirección y en un período más reciente, la entrada en vigor del Real Decreto-ley $33 / 1978$, de 16 de noviembre, sobre mayoría de edad ha

(3) Revista General de Derecho, núms. 382-383, 1976, págs. 699-701.

(4) Como es sabido. la denominada "Ley de Seguridad del Estado», de 29 de marzo de 1941, introdujo en su artículo 42 la privación de la nacionalidad española como sanción penal (si bien como medida gubernativa figuraba en el artículo 9 de la Ley de Delitos monetarios y en el artículo 9 de la Ley de Responsabilidades Políticas de 9 de febrero de 1939), aunque su ámbito se restringirá a partir del Código penal de 1944 al reservar los artículos 34 y 141 esta pena para los «españoles naturalizados». No obstante, con posterioridad, la situación se complicó extraordinariamente con la Ley de 17 de julio de 1945 por la que se aprobaba con carácter de Ley Fundamental el Fuero de los Españoles, al disponer su artículo 20 que «Ningún español podrá ser privado de su nacionalidad sino por delito de traición...». En consecuencia, a partir de aquí, era posible aplicar la sanción a todos los españoles. 
afectado al derecho de opción de la nacionalidad española contenido en el artículo 18 del Código Civil. Al disponerse en este último que los interesados pueden hacer la declaración de opción «dentro del año siguiente a su mayor edad o emancipación», resultaba que los extranjeros comprendidos entre los 19 y 22 años mayores de edad o emancipados conforme a su.ley personal quedaban privados del ejercicio del mencionado derecho. Afortunadamente la disposición adicional primera permite un cauce de solución al problema enunciado al disponer que «en ningún caso se perjudiquen los derechos o situaciones favorables que el ordenamiento concediera a los jóvenes o a sus familiares en consideración a ellos hasta los 21 años de edad" (5).

Consecuentemente, el Derecho de la nacionalidad no presenta, en principio, unos rasgos distintivos en cuanto al carácter retroactivo de sus disposiciones respecto al resto del Ordenamiento jurídico (6). Esto es lo que, al menos, se desprende del enunciado de la disposición transitoria de la Ley 14/1975, de 2 de mayo, y, sobre todo, del razonamiento efectuado por la DGRN en su Resolución de 26 de noviembre de 1977, a propósito de un supuesto de opción de la nacionalidad española por razón de matrimonio, de un extranjero que lo contrajo con española con anterioridad a la referida Ley 14/1975. Según el Alto Organismo

«... de acuerdo con la doctrina más autorizada, los problemas de derecho intertemporal provocados por las sucesivas modificaciones del Código Civil deben ser resueltos a la luz de lo que

(5) Bien entendido que el problema intertemporal sólo se suscitaría si rebajamos el plazo para la opción previsto en el artículo 226 del Reglamento del Registro Civil a los dieciocho años. Vid. con carácter general, M. Peña y Bernaldo de Quirós, «Comentario al artículo 18 del Código civil", Comentarios al Código Civil y Compilaciones Forales (M. Albadalejo ed.), Madrid, Edersa, 1978, págs. 606-608; C. Villan Durán en la obra dirigida por J. D. González Campos, Lecciones de Derecho internacional privado (Derecho de la nacionalidad. Derecho de extranjería), Oviedo, Serv. Publ. Universidad, 1979, pág. 35, y L. I. Sánchez Rodríguez, «La cuestión previa en el Derecho español de la nacionalidad», Anuario de Derecho Civil, 1977, pág. 784.

(6) Tras la reforma del derecho de la nacionalidad operada por la Ley de 15 de julio de 1954, el artículo 19 del Decreto de 2 de abril de 1955 estableció, con claridad, el carácter irretroactivo del núm. 3 del artículo 17 del Código Civil. En la misma línea se sitúa la Resolución de la DGRN de 20 de abril de 1978 que, refiriéndose a la mencionada reforma, afirmó que «de acuerdo con la doctrina científica más autorizada, las sucesivas reformas del Código Civil, en cuanto a los problemas de Derecho intertemporal que las mismas plantean y que no hayan sido expreamente resueltas por el legislador, deben regirse por las disposiciones transitorias del mismo cuerpo legal... parece obvio que conceder eficacia retroactiva al artículo $17,3 .^{\circ}$ del Código iría en perjuicio de la correspondiente nacionalidad extranjera anteriormente adquirida» (Bol. Inf. M. Justicia, núm. 1.130, 5 mayo 1978, pág. 71). 
disponen con carácter general las disposiciones transitorias del propio Código, por lo que es de aplicación al caso lo ordenado por el inciso segundo de la disposición transitoria primera (sic.)... por lo tanto el aludido nuevo derecho de opción debe aplicarse con carácter retroactivo a favor de maridos extranjeros que hubieran contraído matrimonio con española con anterioridad a la entrada en vigor de la Ley 14/1975...» (7).

B) No ocurre así en el Derecho de extranjería debido a que, en palabras de B. Goldman, la condición de los extranjeros no es una «situación instantánea» (8), sino que se prolonga en el tiempo. Las oscilaciones de la economía mundial en el campo de la extranjería es una buena muestra de ello; baste señalar, a este respecto, dos situaciones. La primera vendría determinada por la aparición de una legislación restrictiva en el Estado de acogida; de esta forma, los derechos que disfrutaban los trabajadores extranjeros emigrantes pueden verse recortados con independencia de cualquier arraigo que éstos hubiesen podido adquirir en el país: las recientes disposiciones sobre mano de obra extranjera en ciertos países europeos llegan a constituir en ocasiones una seria excepción a la regla general de la irretroactividad de las leyes. La segunda la encontramos en la reciente normativa española restrictiva en materia de extranjería. Curiosamente se intenta prolongar esta situación incluso con posterioridad a la entrada en vigor de la Constitución. Por ejemplo, en materia de expulsión de extranjeros el texto de base continúa siendo el Decreto 522/1974, cuya ausencia de las mínimas garantías para los derechos del individuo objeto de la medida era característica de la legalidad anterior. Pues bien, este estado de cosas, inadmisible tras la Constitución, se trata de mantener inalterado a pesar de lo previsto en el núm. 3 de su Disposición derogatoria. De este modo se ha expresado, al menos, el Fiscal General del Estado en su Consulta núm. 1/1979, de 12 de enero, sobre adecuación del Ordenamiento jurídico a las normas constitucionales en el sentido de que

«... en tanto no se atribuya la comptencia y se articule el procedimiento judicial para la detención y expulsión de extranjeros indeseables... materias regidas hoy por el Decreto de

(7) Bol. Inf. M. ${ }^{\circ}$ Justicia, núm. 1.116, 15 diciembre 1977, pág. 137.

(8) Cf. B. Goldman, Les conflits de lois dans le temps en Droit international privé, París. Institut des Hautes Etudes Internationales, Curso 1970-71 (policopiado), pág. 4. 
extranjería (sic.) 522/74, de 14 de febrero... las normas... habrán de mantener su plena vigencia, pues de otra forma se crearía un vacío legal inadmisible en un Estado de Derecho» (9).

Lo verdaderamente inadmisible en un Estado de Derecho es, precisamente, la afirmación transcrita del Fiscal General que, por la vía de evitar un hipotético «vacío legal», vacía precisamente de contenido el sistema de derechos y libertades recogidos en la Constitución (10).

C) Por lo que respecta al plano del Derecho procesal civil internacional se plantean en principio menores problemas de Derecho intertemporal, sobre todo debido a que el sistema español ha permanecido aproximadamente un siglo sin modificaciones sustanciales. Sin embargo, la posibilidad está abierta por la vía convencional, conforme disponen los artículos 70 y 951 de la LEC. La reciente ratificación por nuestro país (Instrumento de 27 de julio de 1977) del Convenio hispano-italiano de asistencia judicial y reconocimiento y ejecución de sentencias en materia civil y mercantil de 1973 abona esta posibilidad (11).

4. Pero donde la incidencia del factor tiempo presenta un interés especial es en el plano del conflicto de leyes. Aquí, entre el momento del nacimiento de una situación jurídica y el de intervención del Tribunal, pueden plantearse tres situaciones diversas: de un lado, el factor tiempo puede afectar a la norma de conflicto del foro en el sentido de producir un cambio en el contenido de la misma (sucesión en el tiempo de la norma de conflicto o conflicto transitorio internacional); de otro, cabe que modifique el Derecho extranjero reclamado por la norma de conflicto (conflicto internacional transitorio); finalmente, es susceptible de alterar el punto de conexión (conflicto móvil) (12). A estos tres supuestos ciertos autores

(9) Bol. Inf. M. ${ }^{\circ}$ Justicia, núm. 1.156, 25 enero 1979, pág. 62.

(10) Vid. nuestros comentarios a la referida Consulta en la obra dirigida por J. D. González Campos, cit. en la nota 5, pág. 155.

(11) BOE, 15 noviembre 1977. En relación con el sistema italiano vid. G. Morelli, «Il riconoscimento delle sentenze straniere ed il nuovo codice di procedura civile», Comunicazioni e Studi, vol. I, 1942, pág. 7 y sigs.

(12) Vid. inter alia, H. Batiffol y P. Lagarde, Droit international privé, t. 1, 6. a ed., París, LGDJ, 1974, págs. 398 y ss. P. Graulich, Introduction à l'étude du Droit international privé, Lieja, Faculté de Droit, d'Economie et des Sciences sociales, 1978, págs. 85 y sigs.; E. Spiro, «The Incidence of Time in the Conflict of Laws», The International and Comparative Law Quarterly, vol. 9, 1960, págs. 357-382. No todos los autores comparten esta división tripartita. A juicio de W. W. Knittel, «Changes either in the substantive or conflicts rules of the forum appear not to raise any problem specific to private international law" (Cf. "The Temporal Dimension in the Conflit of Law Rules", British Year Book of International Law, vol. XL. 1964, pág. 105). 
agregan los denominados "conflictos de anexión", que son aquellos que surgen de la aplicación de normas sucesivas resultantes de una modificación de la soberanía estatal en un determinado territorio (13).

5. Pues bien, la referida Sentencia de la Audiencia Territorial de Granada pone el acento en la primera de las dimensiones apuntadas al afirmar al final de su razonamiento que

«... la normativa vigente del nuevo artículo 9, apartado 10 , del Código Civil, en cuanto pudiera significar alguna desviación del concepto de domicilio, a los efectos previstos en la mentada norma, o sea, como norma de conflicto, no podría tener aplicación, por razón de irretroactividad a la fecha en que se produjo la muerte del Sr. Swinkels»

Se trata aquí, como puede observarse, de un típico problema de sucesión en el tiempo de la norma de conflicto del foro, del que la doctrina clásica del Derecho internacional privado ha tenido ocasión de pronunciarse reiteradamente. No es éste el momento de exponer las soluciones adoptadas por los autores acerca del carácter retroactivo o irretroactivo de la norma de conflicto, por contraposición al resto de las normas del Ordenamiento jurídico, sobre todo tras la entrada en vigor de un nuevo sistema conflictual (recuérdese la polémica que suscitó la aparición de la Ley de Introducción al Código Civil alemán de 1900) (14). Y no lo es, entre otras causas, porque existe una excelente síntesis realizada por A. Ortiz-Arce, fruto de sus experiencias en la Sesión del Centro de Investigación de la Academia de La Haya de 1972 (15), que ha venido a llenar una importante laguna en

(13) Cf. B. Goldman, op. cit. en la nota 8, págs. 10-11.

(14) J. Diena, «De la rétroactivité des dispositions legislatives de Droit international privé», Journal du droit international privé, 1900, pâgs. 937 y sigs.; D. Anzilotti, «La questione della retroattività delle regole di Diritto internazionale privato». Rivista di Diritto internazionale, 1907 (reproducido en sus Scritti di Diritto internazionale privato, Padua, 1960, págs. 377-391); A. Giardina, Successione di norma di conflitto, Milán, Giuffrè, 1970, págs. 16-21 (con abundante documentación bibliográfica y jurisprudencial); B. Schneider, "L'application dans le temps des nouvelles règles de conflit. L'expérience allemande", Annuaire suisse de droit international, vol. XXVIII, 1972, págs. 164 y sigs.

(15) A. Ortiz-Arce, «EI Derecho internacional privado y sus problemas de validez temporal», en M. Aguilar Navarro, Derecho internacional privado, vol. I, t. II, parte primera, 3. ${ }^{a}$ ed., Madrid, Secc. Publ. Univ. Complutense. 1977 (reimpresión), pág. 135 y sigs. 
la doctrina española (16). Baste indicar que en la hora actual la mayoría de los autores se inclinan decididamente por la solución del problema con el concurso de las normas generales internas sobre irretroactividad de las leyes; si bien existen posiciones más matizadas.

No obstante, no todos los supuestos de sucesión en el tiempo de la norma de conflicto pueden solucionarse aplicando las mismas reglas. La lectura de las tres monumentales monografías que han jalonado la evolución más reciente de los denominados conflictos de leyes en el tiempo en relación con nuestra disciplina (el vol. II de la de P. Roubier, de 1934, la de Ch. Gavalda, de 1955, y la de A. Giardina, de 1970) (17) nos conduce a plantearnos una serie de hipótesis posibles que encuentran, en relación con el caso que nos ocupa, una relevancia singular. En efecto, el caso «Swinkels c. Swinkels» tiene un carácter restringido al encuadrarse en una de las distintas situaciones en presencia que suscita la sucesión en el tiempo de la norma de conflicto. Debe conjugarse una nueva variable, que vendrá determinada por la naturaleza (legislativa, consuetudinaria o jurisprudencial, o convencional) de dicha norma.

De este modo, las posibles hipótesis pueden reducirse, de forma sumaria, a seis:

a) Sucesión en el tiempo de normas de conflicto legislativas.

b) Sucesión en el tiempo de normas de conflicto de carácter jurisprudencial o consuetudinario.

c) Norma de conflicto legislativa en vigor, modificada por otra de carácter jurisprudencial o consuetudinario.

(16) Baste señalar que la doctrina española se inclina abiertamente por el principio de irretroactividad de las normas de conflicto. Entre los autores que constituyen una excepción a la laguna indicada merecen destacarse J. Yanguas Messía, para quien «estos conflictos, a falta de Derecho transitorio universal, deben ser resueltos por los principios transitorios generales del ordenamiento legislativo en que el cambio de normas se produjo" (Derecho internacional Privado. Parte general, 3. a ed., Madrid, Reus, S. A., 1971, pág. 304); M. Aguilar Navarro y, sobre todo, A. Miaja de la Muela, quien estima que «no hay razón alguna para desviarse en su solución del criterio del correspondiente Derecho interno. Generalmente conducirá esta asimilación al respeto de los derechos adquiridos» (Derecho internacional privado, I, 7. ${ }^{a}$ ed., Madrid, Atlas, 1976, pág. 365). También son dignos de mención los trabajos de W. Goldschmidt, «Apostillas al Derecho transitorio», Revista Crítica de Derecho Inmobiliario, 1943, págs. 606-620, y «Sistema formal del derecho de colisión en el espacio y en el tiempo», Revista Crítica del Derecho Inmobiliario, 1944, págs. 705-720, y 1945, págs. 42-58.

(17) P. Roubier, Les conflits de lois dans le temps (théorie dite de la non-rétroactivité des lois), París, 1933; Ch. Gavalda, Les conflits dans le temps en Droit international privé, París, Sirey, 1955; A. Giardina, op. cit., en la nota 14. 
d) Norma de conflicto de carácter consuetudinario o jurisprudencial, modificada por otra posterior de carácter legislativo.

e) Norma de conflicto legislativa, modificada por otra contenida en un tratado internacional.

f) Sucesión en el tiempo de normas conflictuales de carácter convencional.

6. La frecuencia de las hipótesis enunciadas está en relación directa con el sistema jurídico ante el que nos situemos. De ahí que las señaladas con las letras c) y, sobre todo, b), sean características de los países anglosajones, debido a la teoría del juge-make law. Los trabajos de F. A. Mann (18) y de J. K. Grodecki (19) abordan, en esta dirección, el «conflict between a statutory rule and judicial rule» con cierto detenimiento, tanto desde la perspectiva del common-law como desde la óptica comparada.

Por el contrario, la posibilidad de que la variante b) pueda originar un verdadero conflicto intertemporal ha sido negada por la doctrina continental, principalmente francesa. En esta dirección, P. Roubier rechazó expresamente la posibilidad de «conflicts dans le temps entre des coutumes ou des jurisprudences successives» sobre la base de que

«Une jurisprudence nouvelle s'applique toujours et dans tous les procès nouveaux, sans que l'on prenne en considération la date à laquelle les faits du procès se sont produits et quand bien même ces faits seraient antérieurs au changements de jurisprudence" (20).

En la misma línea se ha pronunciado recientemente P. Graulich, megando la existencia de conflictos intertemporales en la hipótesis b), conclusión que, dada las características de la escala de fuentes del Derecho español, es igualmente válida para el mismo. Por el contrario, mayores problemas plantea para el autor citado la variante c), si bien se inclina por una respuesta positiva. Entre otras razones señala el importante papel que juegan las normas consuetudinarias en el Derecho internacional privado

(18) F. A. Mann, "The Time Element in the Conflict of Law», British Year Book of International Law, vol. XXXI, 1954, págs. 217-247.

(19) J. K. Grodecki, "Conflicts of Law in Time», British Year Book of International Lain, vol. XXXV, 1959, págs. 58-83.

(20) P. Roubier, "Les conflits de lois dans le temps en Droit international privé», Rev. Crit. Dr. Int. Pr., 1931, págs. 55 y sigs. 
francés que poseen —a su juicio— une «stabilité telle qu'elles peuvent être considérées, sur ce plan, comme équivalant à des règles législatives» (21). La transcripción de este razonamiento al Derecho internacional privado español es más que dudosa, sobre todo, a partir de las situaciones creadas con posterioridad al Título Preliminar del Código Civil. El único precedente favorable, la Sentencia Tribunal Supremo de 6 de noviembre de 1867 («M. D. Vázquez c. F. J. e I. Disdier») (22) debe rechazarse por estar formulada en un período histórico completamente superado.

7. La norma de conflicto que rige el estatuto personal de los apátridas se presta admirablemente para poner de relieve el juego del resto de las

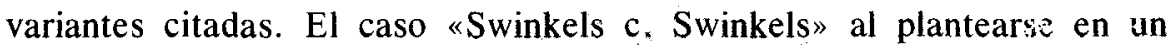
período de inexistencia de norma de conflicto legislativa y ser resuelto por la Audencia con posterioridad a la entrada en vigor del nuevo art. $9,10 .^{\circ}$ del Código Civil se incluye plenamente en la hipótesis d). Sin embargo, no está de más hacer alusión al resto de las posibilidades. Ello por dos motivos. De una parte, para constatar la verdadera dimensión del problema; de otra, para llamar la atención sobre futuras cuestiones que sin duda se suscitarán en nuestro sistema de Derecho internacional privado con la eventual entrada en vigor del Convenio de Nueva York de 1954 sobre el estatuto de los apátridas.

\section{§ 3. SUCESION EN EL TIEMPO DE NORMAS DE CONFLICTO LEGISLATIVAS}

8. La ley de Introducción al Código civil alemán, de 18 de agosto de 1896, incluyó en materia de estatuto personal del apátrida una singular conexión: la ley de su última nacionalidad. En concreto el $§ 29$ disponía que

«Si una persona no pertenece a ningún Estado, siempre que las leyes del Estado al cual una persona pertenece sean declaradas competentes, sus relaciones jurídicas se regulan según las leyes del Estado al que la persona ha permanecido últimamente» (23).

(21) P. Graulich, v. ${ }^{0}$ «Conflit de lois dans le temps», Encyclopédie Dalloz, Dr. Int., I, París, 1968, núm. 19.

(22) RGLJ, Jurisp. Civ., t. 16, 1867, págs. 340 y sigs.; Prácticas..., op. cit. en la nota 2. págs. 166-167.

(23) Cátedra de Derecho internacional privado de la Universidad Complutense, Textos y Materiales de Derecho Internacional Privado, vol. I (Textos y Documentos), Madrid, Secc. Publ. Univ. Complutense, 1970, pág. 182. 
Con ello el legislador alemán intentaba conservar hasta sus últimas consecuencias la relación entre la persona privada de la nacionalidad y el Estado del cual ésta había sido súbdita. Todo ello en la línea tan querida al Derecho alemán de la máxima iura ossibus inheret. Pues bien, tras la masiva entrada de refugiados rusos en Alemania durante los años treinta, la aplicación de «la última ley nacional» traía como consecuencia la aplicación automática por parte de los Tribunales del Reich del Derecho soviético (una vez solventado el problema del reconocimiento del Gobierno de los Soviets) y ello en modo alguno encajaba con la práctica judicial nacionalsocialista. De ahí que para obviar este problema, el párrafo 25 del $\$ 7$ de la Familienrechtsänderungsgesetz de 12 de abril de 1938 modificase la conexión anterior (junto con la lex domicilii que figuraba en el $\S 29$ de la Ley de Introducción como subsidiaria) por la «residencia habitual» (24).

Con esta sustitución de la conexión surgió en Alemania el problema de la aplicación temporal de la nueva norma. «Avrebbe dovuto essa applicarsi solo ai casi verificasti dopo la sua entrata in vigore - se cuestiona A. Giardina- o anche ai casi precedenti tale momento?» (25). Como ha puesto de relieve B. Schneider, la solución al interrogante puede comprobarse en un caso concreto planteado en 1960 ante el Oberverwaltungsgerecht de Munster. Ante un asunto relativo a la sucesión de un título de nobleza ruso abolido por el Derecho soviético en 1938, dicho Tribunal administrativo aplicó con carácter retroactivo el $\S 29$ del EGBGB sobre la base de que el padre del interesado no había tenido contacto jamás con el régimen soviético. Dicha solución fue justamente criticada por el profesor suizo pues, según él

"L'abolition d'un titre de noblesse est un fait accompli: en l'ocurrence elle est intervenue conformément à la loi déclarée applicable par la règle allemande de conflit de l'époque: le titre ne saurait revivre par application de la loi matérielle allemande, désignée par la nouvelle règle de conflit» (26).

9. En esta misma dimensión retroactiva, pero vinculada con el supuesto de las modificaciones territoriales suscitadas por una sucesión de Estados, se encuentra, en la jurisprudencia francesa, la Sentencia de la Cour

(24) J. C. Fernández Rozas, «La ley rectora del estatuto personal del apátrida», Anuario de Estudios Sociales y Jurídicos (Universidad de Granada), 1979 (en prensa).

(25) $C f$. A. Giardina, op. cit. en la nota 14 , pág. 39.

(26) $C f$. B. Schneider, loc. cit. en la nota 14, pág. 170. 
d'Appel de Colmar de 14 de noviembre de 1929 (27). Se trataba aquí de la sucesión del Sr. Gutman, nacido en Alsacia y emigrado a Argentina en 1890. En el momento de salir de Alsacia el de cujus poseía la nacionalidad alemana, pues dicho territorio pertenecía en aquellos momentos a la soberanía alemana. Fijado su domicilio en Buenos Aires, el Sr. Gutman recibió años más tarde un documento expedido por las autoridades alemanas en el que se le comunicaba la pérdida de la nacionalidad y, al no nacionalizarse argentino, se convirtió en apátrida. Posteriormente se trasladó a Suiza, falleciendo en Ginebra en 1915.

La cuestión principal planteada ante el Tribunal era la de saber si podía ser aplicable a la devolución de la sucesión la ley alemana, designada por la norma de conflicto en vigor en el momento del fallecimiento («ley de la última nacionalidad») o la ley designada por la norma de conflicto francesa introducida en Alsacia por Ley de 24 de julio de 1921 y en vigor en el momento de someterse el asunto ante el Tribunal («ley del último domicilio»). No obstante, de seguirse esta última conexión se planteaba un problema ulterior: ¿cuál era el último domicilio del de cujus? Si se determinaba que Buenos Aires, sería entonces de aplicación la ley argentina; por el contrario, si se declaraba Ginebra, la ley suiza seria la que regiría la devolución de la sucesión. Precisamente para obviar este segundo problema el Tribunal de Colmar decidió aplicar la norma de conflicto alemana. Dicha elección entre dos normas de conflicto sucesivas se justificó -a juicio de B. Goldman- al carácter más completo de la primera de las conexiones y a que la fecha del fallecimiento es la que determina los derechos de los herederos a la sucesión. La variación ulterior de la norma no modifica, en consecuencia, la situación creada al amparo de la primera. Según el profesor francés, en este caso «c'est bien évidemment une application très simple et très claire de la règle de droit transitoire interne» (28).

10. La perspectiva española reduce extraordinariamente las dificultades de solución a los problemas apuntados por cuanto, desde el punto de vista general, hasta la reforma del sistema conflictual de 1974 no existía norma alguna que regulase la ley aplicable al estatuto personal del apátrida (29). Sin embargo, en el terreno de las hipótesis es posible un conflicto

(27) Journal du droit international, 1930, pág. 1.039.

(28) B. Goldman, op. cit. en la nota 8, págs. 57-58.

(29) Sobre la nueva norma reguladora de la ley rectora del estatuto personal del apátrida vid. E. Pérez Vera. "Comentario al art. 9, 10 del Código Civil», Comentarios a las reformas del Código Civil, vol. I. Madrid, Tecnos, 1977, págs. 495-499; M. Aguilar Benítez de Lugo, "Comentario al artículo 9 del Código civil», en el colectivo cit. en la nota 5, págs.'197-199;

J. C. Fernández Rozas. loc. cit. en la nota 24. 
intertemporal ante una situación creada al amparo del artículo 4 del Dahir de 1 de junio de 1914 sobre la condición civil de los españoles y extranjeros en el Protectorado español en Marruecos, a cuyo tenor

«Los extranjeros sin nacionalidad conocida o a quienes no pueda atribuirse nacionalidad determinada, residentes en la zona española, estarán sometidos, en lo concerniente a su estado civil, a su capacidad y a los derechos y deberes de familia, al Código Civil español» (30).

La conexión contenida en el precepto transcrito es de dudosa calificación, pues si bien bordea la solución lex fori, no puede incluirse propiamente dentro de ésta al referirse exclusivamente a los «residentes en la zona española». De cualquier forma, ante un supuesto planteado en la actualidad ante nuestros Trihunales por una situación creada al amparo del referido artículo 4 , ¿tendría en este caso la ley de la residencia habitual del artículo 9, 10 del Código Civil efectos retroactivos, o habría que estar a la lex fori?

La respuesta al interrogante se complica por el hecho de que el Decreto 1836/1974, de 31 de mayo, guarda silencio sobre el régimen transitorio a seguir (31), y ante esta omisión habría que poner de manifiesto el tema del eventual carácter retroactivo de la norma de conflicto en el Derecho español: ¿deberán primar los derechos adquiridos, o debe de estarse a la nueva conexión en base a la especialidad de la norma? La primera solución cuenta hoy con los plácemes de la doctrina, pero en estricta aplicación de

(30) Textos y Materiales, op. cit. en la nota 23, pág. 41. La aparición del Dahir de 1913 para la Zona Francesa de Marruecos planteó un interesante problema de Derecho intertemporal a propósito de la ley rectora al régimen económico matrimonial, en la famosa Sent. de la Cour d'Appel de Rabat de 24 de octubre de 1950 («Machet c. Revelu»)' ampliamente comentada por la doctrina (Rev. Crit. Dr. Int. Pr., 1952, págs. 89 y sigs.). Vid. inter alia, Ph. Francescakis, Jurisprudence de Droit international privé, París, Sirey, 1961, págs. 41-55; B. Goldman, Journal du droit international, t. 78, 1951, págs. 898 y sigs.; id. op. cit. en la nota 8, pág. 9; H. Batiffol, «Principes de Droit international privé», Recueil des Cours de l'Académie de Droit international de La Haye", 1959) II, págs. 490 y sigs.; R. Quari, Lezioni di Diritto internazionale privato, 5. ${ }^{\mathrm{a}}$ ed., Nápoles, 1959, págs. 145 y sigs.; A. Giardina, op. cit. en la nota 14, págs. 134-135.

(31) La Sentencia del Tribunal Supremo (Sala 3.a) de 14 de noviembre de 1974 planteó indirectamente el problema intertemporal respecto a la recepción de los tratados en el Derecho interno español. Recuérdese que la Ley de Bases de 1973 consagraba una concepción dualista, en tanto que el actual artículo $1,50^{\circ}$ del Código Civil se inclina por la tesis monista, Vid. la nota de L. I. Sánchez Rodríguez en Revista Española de Derecho Internacional, vol. XXX, 1977, pág. 126. 
las disposiciones transitorias del Código Civil —complementarias del actual párrafo $3 .^{\circ} \mathrm{del}$ artículo 2 de este cuerpo legal-y considerando al Derecho internacional privado como «Derecho de aplicación del Derecho», el tema es susceptible de un examen más pormenorizado que desborda las pretensiones de la presente nota. Nos limitamos, pues, a dejarlo simplemente apuntado.

\section{§4. NORMA DE CONFLICTO CONSUETUDINARIA O JURISPRUDENCIAL MODIFICADA POR UNA NORMA DE CONFLICTO LEGISLATIVA}

11. Es ésta, propiamente, la hipótesis suscitada por la Audiencia Territorial de Granada. Los hechos fueron, en esencia, los siguientes: D. W. H. Swinkels, nacional holandés y domiciliado en los Países Bajos, estaba casado con una súbdita holandesa de la que tuvo cuatro hijos. En las postrimerías de la segunda guerra mundial fue internado en un campo de concentración por los aliados, del cual logró escapar, refugiándose, con ayuda de un pasaporte falso, en Irlanda. Una vez allí, el Sr. Swinkels se divorció de la primera esposa, contrayendo matrimonio civil con la también súbdita holandesa E. Boortman, de la que tuvo una hija. El Sr. Swinkels perdió la nacionalidad holandesa por la actitud demostrada durante la ocupación alemana, siendo confiscados sus bienes por el Gobierno holandés. No obstante, pronto aparece como director - que lo fue hasta el momento de su muerte- de la empresa «Distributors Peugeot (Ireland) Limited», registrada en Irlanda, domiciliado como apátrida en Dublín, con número telefónico a su nombre y titular de varias cuentas corrientes en Bancos irlandeses.

Años más tarde y, al parecer, por razones de salud, el Sr. Swinkels se trasladó a España, fijando aquí su residencia, obteniendo sucesivas tarjetas de residente. En todos los documentos españoles figuraba su domicilio en Marbella; asimismo, tenía allí teléfono a su nombre y era, igualmente, titular de varias cuentas corrientes en Bancos españoles. Ya en España, el Sr. Swinkels otorgó testamento el 16 de diciembre de 1968, en el cual, después de reconocer la existencia de su primer matrimonio y de los cuatro hijos habidos del mismo (respecto de los cuales declaró que le habían abandonado), instituía conforme el Derecho irlandés como única y universal heredera a su segunda esposa. 
El 23 de junio de 1971 falleció el Sr. Swinkels en Marbella y unos meses después su hijo mayor presentó ante el Juez de Primera Instancia de dicha localidad demanda de juicio declarativo de mayor cuantía sobre nulidad de institución de herederos, por preterición de herederos forzosos, contra la Sra. Swinkels. En un primer momento el hijo planteó la demanda sobre la base de la aplicación del Derecho holandés (ley nacional del causante en el momento del fallecimiento, de acuerdo con el antiguo artículo $10,2 .^{\circ}$ del Código Civil) alegando que su padre no había perdido la nacionalidad holandesa (el Derecho holandés no deja libertad de testar); sin embargo, sorprendentemente, en la réplica reconoció la cualidad de apátrida del de cujus. Renunciada a esta vía, el asunto se limitaba ya a determinar cuál era la ley rectora del estatuto personal del apátrida en nuestro Derecho.

Llegados a este punto, el silencio del legislador en la materia obligó al juez a quo a elaborar por sí mismo una norma aplicable. Para ello tenía a su disposición una serie de índices tanto en el plano legal, como en el jurisprudencial como, sobre todo, en el doctrinal.

A) En relación con la dimensión legal se contaba, en primer lugar, con el artículo 96 de la Ley del Registro Civil de 8 de junio de 1957, el cual declara con valor de simple presunción, en virtud de expediente gubernativo, «La nacionalidad, vecindad o cualquier estado, si no consta en el Registro»y, refiriéndose a los apátridas «el domicilio». Con mayor claridad se contaba, en segundo lugar, con el preámbulo del Decreto de 22 de febrero de 1957, sobre reciprocidad en materia de arrendamientos urbanos, el cual, si bien en el contexto del Derecho de extranjería, afirmaba que cuando es "materialmente imposible la referencia al estatuto nacional del extranjero», en base a «nuestra tradicional hospitalidad» (sic.), "parece lógico y humano hacer aplicación del de la Ley del domicilio». Finalmente, en el momento de sustanciarse el pleito ante el Juzgado acababa de aparecer publicada en el $B O E$ la Ley 3/1973, de 17 de marzo, de Bases para la modificación del Título Preliminar del Código Civil, en cuyo artículo 2 , Base $4 .^{\mathrm{a}}$, apartado $6 .^{\circ}$, se disponía expresamente que

«A las personas que careciesen de nacionalidad o la tuvieren indeterminada les será de aplicación, a los efectos de esta base, la ley del lugar de su domicilio o residencia».

Pese a lo equívoco del texto transcrito por identificar dos conexiones tan distintas, no cabe duda que la tendencia del legislador se inclinaba, en la 
línea del Derecho comparado, hacia la conexión domiciliar y, asimismo, trataba de incorporar, por vía indirecta, la conexión contenida en el artículo $12,2 .^{\circ}$ de los Convenios de 1951 sobre refugiados y de 1954 sobre apátridas.

B) Por el contrario, la dimensión jurisprudencial era más parca en precedentes. No obstante, merece destacarse, por ser expresión de una marcada concepción política manifestada por los Tribunales españoles en épocas pasadas, el Auto del Juzgado de Primera Instancia núm. 20 de Madrid de 7 de febrero de 1951. Ante una declaración de herederos $a b$ intestato solicitada por el hermano de un súbdito checo domiciliado en España, el Juzgado realizó estas curiosas reflexiones:

«Cdo.: Que la rigurosa aplicación de la norma de Derecho formal -artículo 10 , párrafo $20^{\circ}$ del Código Civil- llevaría a la inexcusable aplicación también de las normas materiales de Derecho sucesorio vigentes en Checoslovaquia en el momento del fallecimiento intestado del causante... y el acreditar este extremo de forma que surta efecto en juicio es jurídicamente imposible, dada la incomunicabilidad en que internacionalmente se encuentra aquel país con el nuestro...

Cdo.: Que frente a tal imposibilidad cabría proponerse la cuestión básica de hasta qué punto puede estimarse vinculado, pese al mantenimiento de su nacionalidad, a las disposiciones estatales de Derecho privado a un exilado por razones obvias, como las del caso que se examina cuando el vínculo político no existe, cuando sobre la nacionalidad - vínculo natural, fundado en razones geográficas, étnicas, de cultura, etc.- se sobrepone un régimen de fuerza, una simple estructura o superestructura de poder, aunque se califique a sí mismo de Estado... Y si no se estiman vinculados política ni jurídicamente, porque considerarlo así sería una irritante ficción, habrá que considerar a tales sujetos en cierto aspecto "apátridas» no voluntarios... y aplicarles, ya una especie de Derecho privado común o internacional, formado por aquellas normas que integran el fondo jurídico sentido por la comunidad internacional, no regida por principios comunistas, concepto éste de difícil formación y tratamiento, ya del Derecho privado del país en que viven, o Derecho de domicilio, lo que ofrece una mayor seguridad de investigación, de aplicación — por el principio «iura novit cu- 
ria»-y de proximidad a la solución de aquellos casos en que aplicada al extranjero la norma de su estatuto personal -artículos $9 .^{\circ}$ y $10 .^{\circ}$, párrafo $1 .^{\circ}$, proposición $1 .^{\mathrm{a}}$, y párrafo $2 .^{\circ} \mathrm{del}$ Código Civil-, aquélla reenvía - devuelve- el asunto a la competencia de la ley del domicilio» (32).

Dejando al margen el problema del reconocimiento internacional y su repercusión en el plano de las relaciones privadas internacionales, del cual nos hemos ocupado en otro lugar (33), y el de la apatridia «no voluntaria», no cabe duda que dentro de las distintas opciones en presencia el juez no dudó en inclinarse por la lex domicilii. En una dirección similar se inclinó, asimismo, la Resolución de la DGRN de 14 de julio de 1965 («Pedro F. c. Registro de la Propiedad»), la cual, refiriéndose al problema examinado, manifestó que

«...es lógico que se tienda a dar una solución para determinar la legislación que habrá de ser aplicada a quienes se encuentran en tal circunstancia [apatridia], problema que la doctrina en base a principios de Derecho internacional privado resuelve de distintas formas, bien por entender competente la última ley nacional cuando ésta es conocida, o bien la de la residencia, o bien la del domicilio, criterio este último más predominante y que aparece seguida también en España...» (34).

(32) Vid. en texto completo de este singular Auto en JCR, «El estatuto personal de los “apátridas" de hecho», Revista de Derecho procesal, vol. VII, 1951, págs. 295-298.

(33) La actitud general mostrada por los Tribunales a este respecto es la de que la falta de reconocimiento de un Gobierno no afecta en modo alguno a las relaciones privadas internacionales ( $C f$. la Sent. del Trib. de Gran Instancia del Sena (Sala I. ${ }^{a}$ ) de 12 de enero de 1966 («Stroganoff-Sherbatoff c. Bensimon»), que afirmó expresamente que «la falta de reconocimiento de un gobierno extranjero no puede entrañar el desconocimiento, por parte de los tribunales franceses, de las leyes de derecho privado, dictadas por tal gobierno con anterioridad a su reconocimiento para el territorio sobre el que ejercía indiscutiblemente su soberanía» (Rev. Crit. Dr. Int. Pr., 1967, págs. 120 y sigs. y nota de Y. Loussouarn; Semaine juridique (JCP), 1967, II, 15.266 y Nota de J. M. Bischoff; vid. texto castellano en Prácticas, op. cit. en la nota 2, pág. 184). En lo que respecta a la práctica de los Tribunales españoles, vid. J. D. González Campos, «Nota a la Sentencia del Tribunal Supremo (Sala $3 .^{a}$ ) de 30 de junio de 1965 ", Revista Española de Derecho Internacional, vol. XX, 1967, págs. 489 y sigs.; J. C. Fernández Rozas, "Nota a la Sentencia del Tribunal Supremo (Sala I. ${ }^{a}$ ) de 12 de marzo de 1973», Revista Española de Derecho Internacional, vol. XXIX, 1976, págs. 188 y sigs.

(34) Aranzadi, Repertorio Jurisprudencia, 1965, núm. 3.702; Prácticas..., op. cit. en la nota 2 , vol. II, $5 .^{a}$ ed., págs. 62-64. 
C) Por último, en el plano doctrinal, la aplicación de la conexión domiciliar al problema de la ley rectora del estatuto personal del apátrida tuvo - si no un carácter general- sí al menos un cierto predicamento en los autores españoles. Partidarios de él fueron J. M. ${ }^{a}$ Trías de Bes (35), J. R. de Orúe (36), J. G. Verplaetse (37), A. Miaja de la Muela (38), J. Peré Raluy (39) y, sobre todo, M. Aguilar Navarro (40).

La solidez de los índices anteriores indujeron al juez de Marbella a solucionar en su Sentencia de 22 de febrero de 1974, el «caso Swinkels» acudiendo a la ley del domicilio, creando, ante el silencio del legislador, una norma aplicable al litigio. De esta suerte el pleito se redujo a un mero problema probatorio en el sentido de determinar cuál era el domicilio del causante en el momento del fallecimiento Marbella o Dublín, fallando el juez en favor de esta última localidad. Consecuentemente, la demanda fue rechazada.

Hasta aquí no se suscitó ninguna cuestión de Derecho intertemporal. Pero quiso el azar que pocos meses después de dictada la sentencia -que fue recurrida ante la Audiencia Territorial de Granada- se operase la modificación del Título Prelimiminar del Código Civil, en cuyo artículo 9,10 se introducirá una nueva conexión en la materia que nos ocupa: «Se considerará como ley personal de los que carecieren de nacionalidad o la tuvieren indeterminada, la ley del lugar de su residencia habitual». In casu, no ofrece ninguna duda que la residencia habitual del Sr. Swinkels habia sido Marbella; por tanto, en estricta aplicación del precepto, el hijo tenía derecho a la legítima, conforme al Derecho español. Sin embargo, esta

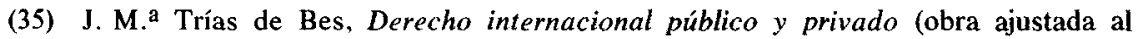
programa de oposiciones al Cuerpo de aspirantes a la Judicatura y al Ministerio Fiscal), Madrid, Reus, 1926, pág. 219 , nota 1; id., Derecho internacional privado. Sistema del Derecho español positivo, 2.a ed., Barcelona, Boch, 1940, pág. 70. Posteriormente, sin embargo, y debido a la influencia del Código italiano de 1942, este autor se inclinó por la conexión «residencia habitual». Así se plasmó en su Proyecto de Título Preliminar de Código Civil de 1962.

(36) J. R. de Orúe y Arregui, Manual de Derecho internacional privado, 3. ${ }^{\text {a }}$ ed., Madrid, Reus, 1952, pág. 50I.

(37) J. G. Verplaetse, Derecho internacional privado, Madrid, Atlas, 1954, pág. 218.

(38) Este autor, refiriéndose a la situación de los refugiados y a la solución contemplada en el artículo $12,1 .^{\circ}$ del Convenio de Ginegra de 1951 (lex domicilli), afirmó expresamente que «más que una rectificación de criterio de los países signatarios de la Convención... hay que ver en este imperio de la ley domiciliar un reconocimiento de la realidad» (A. Miaja de la Muela, «Nota al estatuto de los refugiados», Revista Española de Derecho Internacional, vol. V, 1952, pág. 150).

(39) J. Pere Raluy, Derecho de la Nacionalidad, Barcelona, Boch, 1955, pág. 226.

(40) M. Aguilar Navarro, Derecho civil internacional, Madrid, Secc. Publ. Univ. Complutense, 1961, págs. 44-45. 
situación de facta pendentia fue hábilmente resuelta por la Audiencia granadina en el sentido de identificar - sobre la base de la Exposición de Motivos del Decreto 1836/1974 y del artículo 40 del Código Civil- el «domicilio» y la «residencia habitual». Ahora bien, por si pudiera existir alguna duda al respecto, afirmó en la Sentencia el carácter irretroactivo de la norma de conflicto.

12. ¿Es correcta esta última afirmación de la Audiencia Territorial de Granada? El interrogante entronca con el parágrafo anterior y pone de manifiesto, una vez más, la deficiencia del Decreto $1836 / 74$, por no incluir normas de Derecho transitorio. Ello obliga a realizar un examen de la jurisprudencia española. En esta perspectiva debemos de tener presente, entre otras, dos importantes decisiones, la Sentencia del Tribunal Supremo de 20 de enero de 1934 (41) y la Sentencia del Tribunal Supremo de 16 de enero de 1963; en esta última el Alto Tribunal afirmó categóricamente que

«Es un principio fundamental que las disposiciones legales no ordenan más que para el porvenir ni rigen más actos que aquellos que se producen con posterioridad a su promulgación, por lo que las situaciones jurídicas creadas al amparo de una norma no pueden ser alteradas sin que el legislador dé expresamente efectos retroactivos a la disposición derogatoria, dado que el respeto a los derechos adquiridos exige que la promulgación de nuevas normas jurídicas no impida que los actos realizados bajo el amparo y vigencia de disposiciones anteriores puedan seguir produciendo efectos jurídicos durante el impero de aquéllas excepto si la norma posterior ordenare expresamente la retroactividad" (42).

Precedentes más operativos para el caso que nos ocupa encontramos en la jurisprudencia francesa. Como ha puesto de relieve P. Roubier (43) tras un examen de la jurisprudencia de los tribunales del país vecino, donde destaca la Sentencia de la Cour de Casation de 3 de noviembre de 1941, se puede deducir que el beneficiario de una sentencia, aunque haya sido apelada, está en posesión de un derecho adquirido que no le

(41) RGLJ, Jurisp. Civ., t. 212, enero-febrero, 1934, págs. 297-312.

(42) Col. Leg. Jurisp. Civ., t. 115, enero de 1963, págs. 153-156.

(43) P. Roubier, "De l'effet des lois nouvelles sur les procès en cours", Mélanges offerts à Jacques Maury, t. II, París, 1960, pág. 525. 
puede ser retirado por una ley nueva promulgada en el transcurso de la instancia de apelación. Pero debe tenerse en cuenta que el referido autor se mueve en el plano de la sucesión de normas legislativas no conflictuales, es decir, parte de la existencia de una norma anterior y no contempla una situación del tráfico privado externo. La cuestión a dilucidar es clara, ¿las reglas jurisprudenciales o consuetudinarias pueden crear, por contraposición a las normas legislativas, verdaderos conflictos de leyes en el tiempo? o, si se quiere, ¿pueden tener las segundas efectos retroactivos sobre las primeras ante una situación de facta pendentia? Como señalase Ch. Gavalda, el primer elemento favorable a una respuesta positiva vendría determinado por la escasez de textos legales donde se contienen las normas de conflicto (44). De ahí que sea menester remontarse en esta materia a la problemática general de las fuentes del Derecho internacional privado para examinar el papel que juega la costumbre en cada sistema.

Ahora bien, la utilización de la conexión domiciliar como determinante de la ley rectora del estatuto personal del apátrida, ¿había adquirido carácter consuetudinario en el Derecho internacional privado español? Evidentemente no, a pesar de los precedentes antes señalados. Por tanto, la afirmación de irretroactividad realizada por la Audiencia Territorial de Granada, aún tratándose de facta pendentia, resulta irreprochable (prescindiendo de la errónea identificación entre domicilio y residencia habitual). Por el contrario, si la lex domicilii hubiese llegado a cristalizar en una norma consuetudinaria, la solución sería, a nuestro juicio, radicalmente diversa. En efecto, ante un conflicto entre costumbre antigua y ley nueva en un supuesto del tráfico jurídico externo, la retroactividad debería primar, en principio, sobre los derechos adquiridos.

\section{§ 5. SUCESION EN EL TEMPO DE NORMAS DE CONFLICTO DERIVADAS DE LA ENTRADA EN VIGOR DE UN TRATADO}

13. Se abordan en este parágrafo, conjuntamente, las hipótesis señaladas con las letras e) y f), esto es, la sucesión en el tiempo de una forma de conflicto legislativa por otra de igual naturaleza, pero contenida en un tratado internacional, y la sucesión de dos normas de conflicto contenidas en tratados.

14. En relación con la ley personal del apátrida, el primer supuesto

(44) Ch. Gavalda, op. cit. en la nota 17, pág. 194 y sigs. 
puede plantearse en cualquier momento en España una vez entre en vigor, si es que nuestro país se adhiere, el Convenio de Nueva York de 1954 sobre el estatuto de los apátridas (45). Téngase en cuenta que su artículo $12,1 .^{\circ}$ dispone expresamente que «El estatuto personal de todo apátrida se regirá por la ley del país de su domicilio o, a falta de domicilio, por la ley del país de su residencia». De otra parte, dicho texto internacional especifíca en el núm. 2 de su artículo 39 que el Convenio entrará en vigor el nonagésimo día siguiente a la fecha del depósito del Instrumento de adhesión, pero no contiene ninguna norma de Derecho transitorio; ¿qué ocurrirá entonces con una eventual situación creada al amparo del artículo 9,10 del Código Civil que se sustancie tras la publicación del citado Convenio en el BOE?; ¿debe estarse a la conexión antigua (residencia habitual) o a la nueva (domicilio)? La solución a estos interrogantes no puede, sin embargo, ser definitiva.

En primer lugar, y como respuesta previsible, puede que el juez obvie el problema intertemporal acudiendo a la identificación entre el domicilio y la residencia habitual que, como vimos en el parágrafo anterior, tiene en el artículo 40 del Código Civil y en la Exposición de Motivos del nuevo Título Preliminar del mismo su máxima expresión. No obstante, esta solución parte de una anomalía existente en el Derecho internacional privado español $y$, por tanto, susceptible de una dura crítica (46). No olvidemos que la confusión entre ambas conexiones puede poner en peligro los legítimos derechos de una de las partes en el litigio: la solución de la Audiencia Territorial de Granada en el caso «Swinkels c. Swinkels» es una buena muestra de ello.

Mucho más correcto sería que nuestro país formulase en el momento de la adhesión al Convenio de Nueva York — si es que se decide a ellouna reserva al artículo $12.1^{\circ}$ Téngase en cuenta que el artículo $38 \mathrm{del}$ citado texto lo permite y que existen precedentes en tal sentido, como las reservas que en su día formularon Suecia y Finlandia (47); aunque también los hay en sentido contrario: el caso de Italia, que al ratificar en 1962 el Convenio nada dijo al respecto a pesar de que el artículo 29 de su Código Civil contiene la conexión residencia habitual, es una buena muestra de

(45) Vid. el texto del Convenio en J. A. de Obieta, El Derecho internacional de la persona humana, Bilbao, ed. Mensajero, 1974, págs. 494-508.

(46) Vid. las certeras observaciones de J. A. Carrillo Salcedo, Derecho internacional privado, 2. a ed., Madrid, Tecnos, 1976, pág. 165 y sigs.

(47) Cf. Traités Multilatéraux pour lesquels le Secrétaire Général exerce les fonctions de dépositaire, ST/LEG/SER.D/8, Nueva York, 1975, págs. 123 y 125. 
ello (48). La inclusión de una reserva en este sentido tiene, claro es, muchas posibilidades de prosperar, sobre todo, tras la adhesión de España al Convenio de Ginebra de 1951. En efecto, al comprobarse la incompatibilidad de la conexión del artículo 9, 10 de nuestro Código Civil con la contenida en el artículo $12,1 .^{\circ}$ de este último Convenio, el Gobierno español formuló una reserva en cuanto a la aplicación del citado precepto (49). Por esta vía, en materia de estatuto personal de los refugiados políticos no cabe plantearse ningún problema intertemporal en la dimensión ahora examinada.

Pero de no darse las circunstancias antedichas (identificación entre el domicilio y la residencia habitual por parte del juez, o eventual reserva al Convenio de 1954), el problema intertemporal es susceptible de aparecer. En tal caso, acudiendo a las soluciones de nuestro Derecho interno, cabría solucionar el mismo acudiendo a la norma general del artículo $2,3 .^{\circ} \mathrm{del}$ Código Civil - $\mathrm{y}$ disposiciones transitorias correspondientes del mismo cuerpo legal-. Pero, de hacer esto, se pondría igualmente en evidencia la deficiencia del sistema español en orden a la jerarquía de las normas convencionales en la escala de fuentes del Derecho que, ni el artículo 1, $5 .^{\circ}$ del Código Civil, ni la Constitución han resuelto plenamente. En todo caso, lo que resulta evidente es que de no ser aplicada la lex domicilii por el juez español, la posibilidad de que nuestro país incurra en responsabilidad internacional no puede descartarse.

15. Finalmente, queremos plantear la hipótesis límite contenida en la letra f) que, si bien nos conduce a un problema clásico del Derecho de los tratados (tratados sucesivos concernientes a la misma materia), ofrece interesantes facetas en relación con el tema de la ley personal del apátrida. Nos referimos al supuesto de que la conexión del artículo $12,1 .^{\circ} \mathrm{del}$ Convenio de 1954, al amparo de la cual se ha constituido determinada relación jurídica, sea modificada por la entrada en vigor de un convenio posterior que contenga una norma expresa en la materia.

El alcance de esta hipótesis podemos comprobarlo - a falta de un

(48) Ibid., pág. 123. Mayor gravedad registra la situación de la Rèp. Argelina tras la publicación de la Ordenanza núm. $75-58$, de 26 de septiembre de 1975 , relativa al Código Civil, pues pese a haber ratificado el Convenio de 1954 el 15 de julio de 1964 (Ibid., pág. 121) estableció en su artículo $22,3 .^{\circ}$ que «en caso de apatridia, la ley aplicable se determina por el juez». Esta solución ha sido justamente criticada por G. Peyrard, "La solution des conflits de lois en Algérie», Rev. Crit. Dr. Int. Pr., 1977, pág. 390.

(49) Instrumento de Adhesión de España a la Convención sobre el Estatuto de los Refugiados, hecha en Ginebra el 28 de junio de 1951, de 22 de julio de 1978 (BOE, 21 octubre de 1978, pág. 24.310). 
precedente relativo a los apátridas - en relación con una situación muy próxima: el estatuto personal de los refugiados, a propósito de la Sentencia del Tribunal de Grande Instance de Compiegne de 13 de abril de 1976 («Dame Mazurek c. Lis») (50). Ante una demanda de divorcio interpuesta por una polaca contra su marido, igualmente polaco, estando ambos cónyuges domiciliados en Francia, se cuestionó la determinación de la ley aplicable al mismo. De acuerdo al artículo 8, 1. ${ }^{\circ}$ del Convenio franco-polaco de 1967 (51), era de aplicación la ley polaca («loi de la Haute partie contractante donc les époux ont la nationalité à la date de présentation de la demande»), pero, dada la cualidad de refugiado del marido, esta situación quedaba afectada por el artículo $12,1 .^{\circ}$ del Convenio de Ginebra de 1951, debiendo aplicarse, consecuentemente, la ley francesa. ¿Qué respuesta damos a un conflicto entre normas de conflicto contenidas en Convenios sucesivos? Si atendemos a la regla general del artículo 30 del Convenio de Viena de 1969 sobre el Derecho de los tratados, debería prevalecer la conexión prevista en el Convenio franco-polaco, ya que Francia se adhirió al Convenio de 1951 en 1954 (bien entendido que el Convenio de Viena no es aplicable al caso en virtud de la norma de irretroactividad contenida en su artículo 4, pero no olvidemos que consagra una costumbre reiterada en la materia). De otra parte, si el matrimonio Lis se hubiese establecido en Francia con anterioridad a 1967 hubiese sido factible la alegación por el marido de un derecho adquirido; pero esto no era posible dado que su fecha de entrada en Francia era posterior.

El juez francés resolvió el problema aplicando la ley francesa sobre la base de que la cualidad de refugiado del demandado obligaba a acudir al artículo 8, 2. ${ }^{\circ}$ del Convenio franco-polaco de 1967 , según el cual

«Si en la fecha de la presentación de la demanda de divorcio uno de los esposos tiene la nacionalidad de una de las Altas Partes contratantes y el segundo la de la otra, el divorcio se declara según la ley de la Alta Parte contratante en cuyo territorio estén domiciliados los esposos o hubieran tenido el último domicilio.»

(50) Rev. Crit. Dr. Int. Pr., 1976, p. 718-720 y Nota de P. Lagarde, págs. 721-723.

(51) Convenio entre la República Francesa y la República Popular de Polonia relativo a la ley aplicable, la competencia y el exequatur en el Derecho de las personas y de la familia, hecho en Varsovia el 5 de abril de 1967. Vid. el texto en Rev. Crit. Dr. Int. Pr., 1969, págs. 329-333, y los comentarios al mismo de R. de Bottini, ibid. 1970, págs. 1-43. Texto castellano en Prácticas..., op. cit. en la nota 2, págs. 142-146. 
Comentando esta decisión y partiendo del resultado justo al que con ella se llegó, P. Lagarde introduce unas certezas críticas. En esencia pone el acento en la inaplicabilidad del precepto transcrito en el asunto como fundamento de la competencia de la ley francesa. Dicha competencia se desprende, a juicio de este autor, de que «la soummission du statut personnel du réfugié statutaire à la loi du pays de son domicile résulte de la Convention de Genève... et que le conflit entre la Convention de Genève et la Convention franco-polonaise doit être tranché en faveur de la première» (52).

(52) P. Lagarde, loc. cit. en la nota 50, pág. 722. 